\section{Subobstructive Symptoms Caused by a Peduncu- lated Polyp of the Terminal Ileum in Stenosing Ileocolonic Crohn's Disease}

We report here the case of a 60-year-old woman with Crohn's ileocolitis, diagnosed 15 years earlier, who presented with a sixmonth history of subocclusive episodes that were initially related to a stricture in the descending colon. After endoscopic dilation of this stricture, further episodes were then related to a narrowing involving the ileocecal valve and terminal ileum, as seen in a follow-up examination of the small bowel, which was also dilated. The recurrence of the symptoms led us to extend the inspection of the ileum beyond the dilated tract and, $10 \mathrm{~cm}$ proximally, a pedunculated polyp measuring $3 \mathrm{~cm}$ was seen. A small-bowel enema confirmed the presence of the polyp (Figure 1). The lesion was then removed endoscopically without complications (Figure 2). The histological examination showed features consistent with 
an inflammatory polyp. Up to ten months after the ileal polypectomy, the patient had not experienced any further subocclusive symptoms.

In Crohn's disease, ileal inflammatory polyps are rare, and have been reported to present with symptoms of obstruction (1) or with refractory iron-deficiency anemia (2). Both of these signs, however, are frequent in Crohn's disease and may be related to the inflammatory intestinal involvement itself. In our patient, inflammatory stenoses and a terminal ileal pedunculated polyp, both potential causes of subobstructive symptoms, coexisted. The recurrence of subocclusive episodes after endoscopic dilation was at first attributed to restenosis. The clinical outcome after the polypectomy revealed the cause of the symptoms. In this patient, retrograde ileoscopy, which should be routinely and deeply performed in cases of suspected or known inflammatory bowel disease $(3,4)$ allowed both diagnosis and treatment.

S. Morini ${ }^{\prime}$, R. Lorenzetti ${ }^{1}$, P. Cerro ${ }^{2}$, F. Stella ${ }^{3}$

' Digestive Endoscopy Unit, Ospedale Nuovo Regina Margherita, Rome, Italy

${ }^{2}$ Radiology Unit, Ospedale Nuovo Regina Margherita, Rome, Italy

${ }^{3}$ Histopathology Unit, Ospedale S. Giacomo, Rome, Italy

\section{References}

1. Corless JK, Tedesco FJ, Griffin JW Jr, et al. Giant ileal inflammatory polyps in Crohn's disease. Gastrointest Endosc 1984; 30: $352-4$.

2. Manning RJ, Lewis C Jr. Inflammatory ileal polyps in Crohn's disease presenting as refractory iron-deficiency anemia. Gastrointest Endosc 1988; 32: 122.

3. Morini S, Lorenzetti R, Manurita L. Diagnostic role of retrograde ileoscopy (RI) in patients with mild chronic undiagnosed diarrhea. Gastroenterology 1993; 104: A748.

4. Zwas FR, Bonheim NA, Berken CA, et al. Ileoscopy as an important tool for the diagnosis of Crohn's disease: a report of seven cases. Gastrointest Endosc 1993; 40: 89-91.

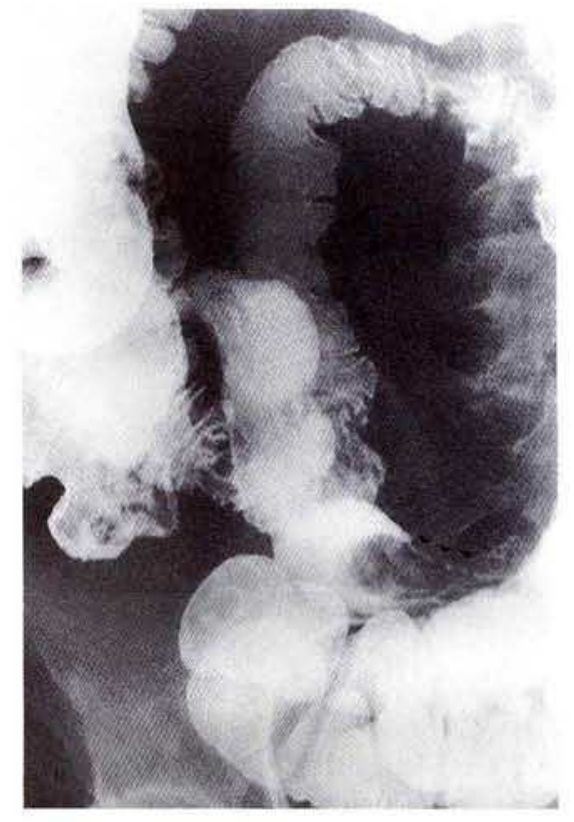

Figure 1: Small-

bowel enema. A large polypoid filling defect is seen in the terminal ileum (arrow).

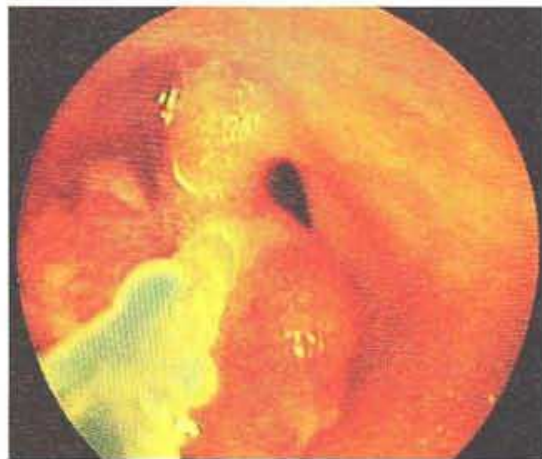

Figure 2: Endoscopic view of the ileal polypectomy.
Corresponding Author

S. Morini

Via Morosini 30

00153 Rome

Italy

Fax: +39-6-68308660 